S.S. Rengachary, E.C. Benzel (eds)

\section{Calvarial and Dural Reconstruction}

Neurosurgical Topics

American Association of Neurological Surgeons, Chicago, 1998

ISBN 1-879284-63-4

We all have many books on our shelves that discuss common topics in neurosurgery, and we could get virtually identical information from any of them. However, occasionally a book comes along that contains truly unique information not readily obtainable from any other source. Calvarial and Dural Reconstruction is just such a bookboth because of its unique topic and because it contains a treasure trove of information. It is an invaluable resource for every neurosurgeon.

The book essentially reviews two different topics. First, it discusses the biomedical properties of calvarial and dural reconstructive materials and the operative principles of reconstructing complex calvarial and dural defects. This topic begins with chapters on the history of calvarial reconstruction (Chapter 1) as well as general overviews of the biomedical properties of various cranioplasty materials (Chapter 3) and dural substitutes (Chapter 4). It follows with separate chapters dealing with the principles and techniques of polymethylmethacrylate cranioplasty (Chapter 5); cranioplasty using autologous bone (Chapter 6); the use of CT imaging data to construct preformed cranial prostheses (Chapter 7); the use of hydroxyapatite (Chapter 8); principles and techniques of scalp reconstruction (Chapter 9); reconstruction of frontal sinus injuries (Chapter 10); reconstruction of the anterior skull base (Chapter 11), and reconstruction of posttraumatic and postoperative skull defects (Chapter 12).

The second and smaller topic includes the pathogenesis, and principles of surgical repair, for the various forms of craniosynostosis. This section begins with a chapter on the pathogenesis and genetics of craniosynostosis (Chapter 2). Separate subsequent chapters review metopic synostosis (Chapter 13), sagittal synostosis (Chapter 14), unilateral and bilateral coronal craniosynostosis (Chapter 15), lambdoid synostosis and posterior plagiocephaly (Chapter 16) and multisutural synostosis (Chapter 17).

The chapters on craniosynostosis are fairly commonplace and, for the experienced pediatric neurosurgeon, add little to that which is already available from other standard pediatric neurosurgical texts. However, these chapters provide a timely and well-referenced review of craniosynostosis for the general neurosurgeon who deals less frequently with children. In particular, the chapter on posterior plagiocephaly provides a reasonable and balanced overview of current theories and controversies regarding the pathogenesis, work-up and treatment of this disorder. I would take minor issue with some of the statements in the chapter. For example, there is evidence to refute the authors' contention that radiographic changes, such as perisutural sclerosis or even partial sutural obliteration, on skull X-rays or CT scans argue against deformational plagiocephaly and instead support a diagnosis of lambdoid synostosis. However, these are minor criticisms of a chapter that, overall, provides a modern and balanced discussion that is missing from many general neurosurgical texts.

There are also overviews of skull growth regulation and current theories of craniosynostosis, including the more recent genetic discoveries involving the importance of fibroblast growth factor receptor gene mutations in the pathogenesis of various craniosynostoses. However, I find these discussions to be a bit weak and somewhat disjointed.

The real jewel in this book for the practicing pediatric neurosurgeon is the larger section on calvarial and dural reconstruction: I learned a great deal from these chapters, many of which are written wholly or in part by plastic and reconstructive surgeons and/or otolaryngologists, adding significantly to the information contained therein. In particular, the chapters on frontal sinus and anterior cranial fossa reconstruction, and the chapter on scalp reconstruction, are well done. There is a wealth of information regarding the chemical and mechanical properties of various cranioplasty materials, as well as the risks, benefits and rationale for their use in chapters dealing with these topics, providing a terrific resource for anyone who uses these materials.

The chapters are all well written and generally well referenced. The figures are of high quality and appropriate to the discussions. I found no significant areas of disagreement among different chapters; in fact, I was surprised at the remarkable consistency between different chapters and authors.

I have a few minor criticisms of the book. Most importantly, from a pediatric neurosurgical perspective, the lack of any discussion about the reconstruction of calvarial malformations such as encephalocele defects and the repair of cutis aplasia congenita is a significant omission and a disappointment. I would have liked to see a more in-depth and organized discussion of the recent genetic advances in craniosynostosis. Some redundancy of information between chapters might have been avoided. For example, a significant overlap of material between chapters 3 and 12 (which were written by the same authors) could have been eliminated by combining these chapters. Finally, a relatively large number of typographical errors should have been corrected in proof. Overall, however, there is little to criticize and a lot to recommend in this book. It is a perfect topic that has been well reviewed; it should grace the shelves of every neurosurgeon.

Mark S. Dias, Buffalo, N.Y.

\section{KARGER \\ Fax + 41613061234}

E-Mail karger@karger.ch www.karger.com

\section{두 1999 S. Karger AG, Basel}

Accessible online at:

http://BioMedNet.com/karger 